\title{
FAST PLASMA SINTERING DELIVERS FUNCTIONAL GRADED MATERIALS COMPONENTS WITH MACROPOROUS STRUCTURES AND OSSEOINTEGRATION PROPERTIES
}

\author{
R.F.Godoy ${ }^{*}$, M.J. Coathup ${ }^{1}$, G.W. Blunn ${ }^{1}$, A.L.G. Alves ${ }^{2}$, P. Robotti ${ }^{3}$ and A.E. Goodship ${ }^{1}$ \\ ${ }^{1}$ Institute of Orthopaedics and Musculoskeletal Science, University College London, \\ Royal National Orthopaedic Hospital, Stanmore, UK \\ ${ }^{2}$ Department of Veterinary Surgery and Anaesthesiology, School of Veterinary Medicine and Animal Science, \\ São Paulo State University, Botucatu, São Paulo, Brazil \\ ${ }^{3}$ Research and Development Department, Eurocoating Spa, Trento, Italy
}

\begin{abstract}
We explored the osseointegration potential of two macroporous titanium surfaces obtained using fast plasma sintering (FPS): Ti macroporous structures with 400$600 \mu \mathrm{m} \varnothing$ pores (TiMac400) and 850-1000 $\mu \mathrm{m} \varnothing$ pores (TiMac850). They were compared against two surfaces currently in clinical use: Ti-Growth ${ }^{\circledR}$ and air plasma spray (Ti-Y367). Each surface was tested, once placed over a Tialloy and once onto a $\mathrm{CoCr}$ bulk substrate. Implants were placed in medial femoral condyles in 24 sheep. Samples were explanted at four and eight weeks after surgery. Push-out loads were measured using a material-testing system. Bone contact and ingrowth were assessed by histomorphometry and SEM and EDX analyses. Histology showed early osseointegration for all the surfaces tested. At 8 weeks, TiMac400, TiMac850 and Ti-Growth ${ }^{\circledR}$ showed deep bone ingrowth and extended colonisation with newly formed bone. The mechanical push-out force was equal in all tested surfaces. Plasma spray surfaces showed greater bone-implant contact and higher level of pores colonisation with new bone than FPS produced surfaces. However, the void pore area in FPS specimens was significantly higher, yet the FPS porous surfaces allowed a deeper osseointegration of bone to implant. FPS manufactured specimens showed similar osseointegration potential to the plasma spray surfaces for orthopaedic implants. FPS is a useful technology for manufacturing macroporous titanium surfaces. Furthermore, its capability to combine two implantable materials, using bulk $\mathrm{CoCr}$ with macroporous titanium surfaces, could be of interest as it enables designers to conceive and manufacture innovative components. FPS delivers functional graded materials components with macroporous structures optimised for osseointegration.
\end{abstract}

Keywords: Bone colonisation, fast plasma sintering, implant, macroporous, plasma spray, sheep, surgery, titanium.

* Address for correspondence:

Roberta Ferro de Godoy

Institute of Orthopaedics and Musculoskeletal Science Brockley Hill, HA7 4LP, Middlesex, UK

Telephone number: +44 (0) 2089095746

Fax number: +44 (0) 2089548560

Email: r.godoy@ucl.ac.uk

\section{Introduction}

An optimal fixation between bone and implant materials is of great importance for successful outcome of total knee arthroplasty and total hip arthroplasty. An implant not well fixed to bone can lead to poor clinical results, with pain and bone resorption resulting from motion at the implant-bone surface (Tsukeoka et al., 2005). The long-term success of bone-interfacing implants for load-bearing orthopaedic and dental applications requires rapid rigid fixation of the implant within the host bone site. This condition, known as functional osseointegration, is achieved in un-cemented and press-fit implant systems by mechanical interlock between the surface features of the implant (threaded, porous, or textured surfaces) and subsequent ingrowth of bone tissue (Simmons et al., 2001). In order to improve bone-implant integration at the implant surface further, highly porous or rough surface treated structures and the use of surface coatings are continuously being investigated (Chen et al., 2011).

Plasma spraying of titanium is one of the most popular techniques used in the fabrication of porous surfaces for un-cemented implants (Ryan et al., 2006; Takemoto et al., 2006). It has been recognised that plasma spraying produces highly porous surfaces with both open and interconnected pores, which vastly improve bone ingrowth characteristics (Chen et al., 2011; Otsuki et al., 2006; Ryan et al., 2006).

Orthopaedic devices with porous coatings have been used as a means to achieve fixation by integration of the implant with osseous tissue (osseointegration). The majority of porous metal coatings are produced by sintering titanium beads, mesh or fibres or by plasma spraying of titanium particulates. Under appropriate conditions, the growth of bone into the porosity of these coatings results in long-term direct mechanical fixation of the implanted device to the host skeleton (Della Valle et al., 2009; Levine et al., 2006).

Recent advances in manufacturing methods have enabled the fabrication of entirely porous metal implants for skeletal repair (Lefebvre et al., 2009; Ryan et al., 2006; Facchini et al., 2009). These new porous structures, as opposed to sintered beads or mesh coatings, have larger porosity and can achieve a good level of integration with bone as required for primary fixation (Baril et al., 2011; Biemond et al., 2011a).

Several new highly-porous metals have been recently introduced to improve the biomaterial properties of these traditional metals, namely porosity, surface coefficient, 
and modulus of elasticity. These new biomaterials all share a microscopic characteristic appearance, which is similar to cancellous bone. The open-cell structure of these materials affords several intriguing properties, including high volumetric porosity (60-80\%) and low modulus of elasticity (Ryan et al., 2006; Matassi et al., 2013). High implant porosity provides more space for bone ingrowth and bone interlocking, which improves the strength of the implant-bone bond (Karageorgiou and Kaplan, 2005; Tarala et al., 2011; Muth et al., 2013). Therefore, production of macroporous metal structures is emerging as a very powerful strategy to achieve reliable and long lasting bone fixation in orthopaedic components (Web Ref 1; Web Ref 2).

Fast plasma sintering (FPS) technology is a relatively new technique. It allows delivery of orthopaedic components from raw materials, either in powder or solid state. FPS consists of a process with very fast heating and cooling phases, and very short holding times. Finally, it releases fully dense samples in a reduced cycle time in comparison to standard processes. By FPS, it is possible to obtain sintered materials with very fine microstructure and generate functionally graded materials (FGM). For instance, FPS can generate a single acetabular cup with several layers of CoCrMo alloy, Ti6Al4V alloy and macro porous interconnected commercially pure $\mathrm{Ti}(\mathrm{CP} \mathrm{Ti})$ foam structure. It is also possible, by FPS, to create a metallic foam onto an already pre-formed ceramic substrate (Godoy et al., 2012; Web Ref 3).

Although the existing coatings, such as the plasma spray coating tested in this study, show high level of roughness and porosity, the novel macroporous structures show greater porosity in terms of $\%$ of porosity, pore size and pore depth. Therefore, we expect that macroporous surfaces will stimulate and enhance the bone ingrowth and the implant fixation. If, in the study, the macroporous surface shows a comparable osseointegration potential to the currently clinically available surfaces, we would use them for acetabular cups and tibial plateau.

This study explored the hypotheses that macroporous titanium surfaces, obtained using the innovative FPS powder metallurgy process, have osseointegration potential. The study had three aims:

1) To assess improvement or equivalence in osseointegration for FPS produced macroporous surfaces against a state of the art plasma sprayed titanium surface and against an innovative titanium plasma spray porous surface (i.e. TiGrowth $^{\circledR}$ ).

2) To assess improvement or equivalence in osseointegration for FGM devices (porous titanium onto $\mathrm{CoCr}$ substrate) against the state of the art for coupling different metals (i.e. plasma sprayed Titanium surface onto $\mathrm{CoCr}$ substrate).

3) To assess differences in osseointegration, if any, for homo-titanium samples against FGM samples (i.e. $\mathrm{CoCr}$ Porous Ti vs. Ti6Al4V-Porous Ti).

Indeed, FPS is expected to give a cost-competitive advantage in manufacturing implantable devices while, at the same time, enhancing the implant through:

- a macroporous surfaces for osseointegration

- a coupling of different materials to accomplish different demanding tasks
- a solution which avoids the risk of dislocation, sometimes possible when they are used separate assembled components

- overpassing thickness constraints in the artificial device.

\section{Materials and Methods}

\section{Implants}

Four different functionally graded components (FGM) specimens have been produced (Eurocoating Spa, Trento, Italy) by fast plasma sintering (FPS), selectively coupling layers of either Ti macroporous structure with pores $\varnothing=400-600 \mu \mathrm{m}$ (TiMac400), or Ti macroporous structure with pores $\varnothing=850-1000 \mu \mathrm{m}$ (TiMac850) (Fig. 1). Both were placed over fully dense Ti6Al4V or fully dense CoCrMo. To control actual pore dimensions, exactly to desired nominal values, Ti macropores were initially filled with hydroxyapatite (HA) granules, later removed by dipping samples in nitric acid to form open and interconnected porosity within the titanium layer.

For comparative purposes, two different clinically-used plasma spray surfaces (Eurocoating Spa, Trento, Italy) were used as controls (Fig. 1): Ti-Growth ${ }^{\circledR}$ - an innovative macroporous vacuum plasma spray titanium coating (porous) - and Ti-Y367 - an air plasma spray titanium coating (rough non-porous). Both were placed over fully dense Ti6A14V, or fully dense CoCrMo. For histological assessment, SEM and EDX evaluation, 4 types of block implants $(8 \mathrm{~mm}$ width $\times 6 \mathrm{~mm}$ height $\times 15 \mathrm{~mm}$ long $)$ with different layer sequences from solid base to highly porous were used (Table 1, Figs. 1 and 2). For push out test, 4 types of cylindrical (rod) implants ( $4 \mathrm{~mm}$ diameter $\times 8 \mathrm{~mm}$ long), one type for each different surface, were used (Table 2 and Fig. 1).

For each implant type, the specimens were produced at the same time (same batch). The inspection was performed using one sample per implant type. Characterisation of the commercial reference specimens was also confirmed by analyses regularly performed during standard production.

Prior to implantation, implants were cleaned in a specific washer for medical devices, packaged and sterilised with gamma rays.

\section{Surgery and implantation procedure}

All animal procedures were carried out under licences granted by the UK Home Office in accordance with the Animals (Scientific Procedures) Act of 1986. The guidelines for the care and use of laboratory animals (Animals (Scientific Procedures) Act 1986) were observed throughout the implantation procedures.

Twenty-four skeletally mature sheep (English Mule, average 75,041 $\pm 6,209 \mathrm{~kg}$ ) were used in this study. Each implant (block or rod) was tested 6 times in different animals, as determined by a power calculation to give statistically significant results (power of $80 \%$ ).

Rod implants were inserted in a press fit fashion into holes drilled (drill bit and reamer $\varnothing=4 \mathrm{~mm}$ ) bilaterally in the cancellous bone ( 2 different rod implants per animal) of the distal medial femur (Fig. 3). 
Table 1. Specification of titanium implant blocks used.

\begin{tabular}{|c|c|c|c|c|c|c|}
\hline & Surface Type & $\begin{array}{l}\text { Surface } \\
\text { Name }\end{array}$ & Thickness & Substrate Material & Thickness & $\begin{array}{l}\text { Abbreviation in } \\
\text { the article }\end{array}$ \\
\hline \multirow{2}{*}{ Block 1} & Porous FPS & TiMac850 & $1,500 \pm 200 \mu \mathrm{m}$ & Ti Alloy (Ti-6Al-4V) & $1,500 \mu \mathrm{m}$ & TiMac850/Ti \\
\hline & Porous Vacuum Plasma Spray & TiGrowth & $800 \pm 200 \mu \mathrm{m}$ & CoCr (ASTM F75) & $2,000 \mu \mathrm{m}$ & TiGrowth/CrCo \\
\hline \multirow{2}{*}{ Block 2} & Porous FPS & TiMac850 & $1,500 \pm 200 \mu \mathrm{m}$ & \multirow{2}{*}{$\mathrm{CoCr}$ (ASTM F75) } & \multirow{2}{*}{$4,000 \mu \mathrm{m}$} & TiMac850/CoCr \\
\hline & Rough Air Plasma Spray & Ti-Y367 & $300 \pm 50 \mu \mathrm{m}$ & & & Ti-Y367/CoCr \\
\hline \multirow{2}{*}{ Block 3} & Porous FPS & TiMac400 & $1,500 \pm 200 \mu \mathrm{m}$ & \multirow[t]{2}{*}{ Ti Alloy (Ti-6Al-4V) } & \multirow{2}{*}{$4,000 \mu \mathrm{m}$} & TiMac400/Ti \\
\hline & Rough Air Plasma Spray & Ti-Y367 & $300 \pm 50 \mu \mathrm{m}$ & & & Ti-Y367/Ti \\
\hline \multirow{2}{*}{ Block 4} & Porous FPS & TiMac400 & $1,500 \pm 200 \mu \mathrm{m}$ & CoCr (ASTM F75) & $2,000 \mu \mathrm{m}$ & TiMac400/CoCr \\
\hline & Porous Vacuum Plasma Spray & TiGrowth & $800 \pm 200 \mu \mathrm{m}$ & Ti Alloy (Ti-6Al-4V) & $1,500 \mu \mathrm{m}$ & TiGrowth/Ti \\
\hline
\end{tabular}

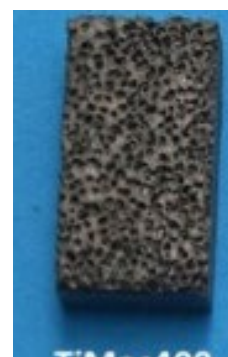

TiMac400

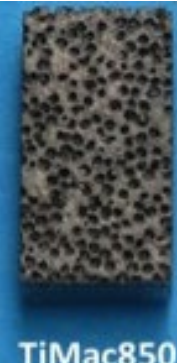

TiMac850

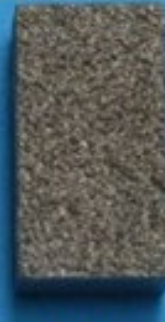

Ti-Y367

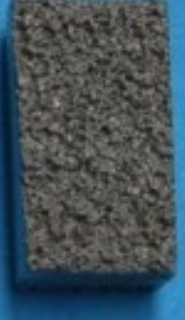

TiGrowth
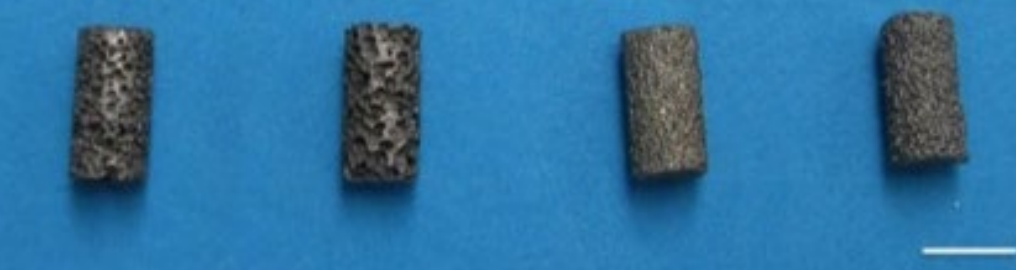

Fig. 1. Specimens. On top the block implants for the histological evaluation showing the four surfaces tested, below the rod implants for the push-out test. (bar $5 \mathrm{~mm}$ ).

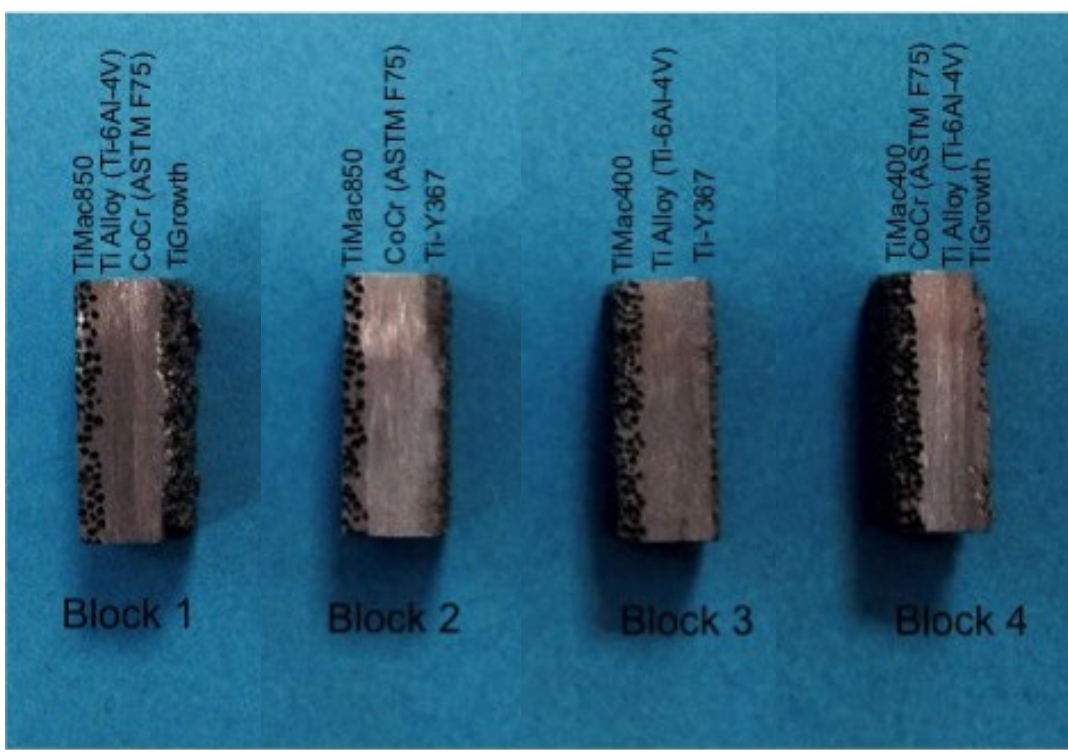

Fig. 2. Specimens (block implants) detailing the layers.

Table 2. Specification of rod implants used.

\begin{tabular}{|l|c|c|}
\hline & Surface Name & Surface type \\
\hline Rod 1 & TiMac400 & Fully Porous FPS \\
\hline Rod 2 & TiMac850 & Fully Porous FPS \\
\hline Rod 3 & Ti-Y367 & Rough Air Plasma Spray \\
\hline Rod 4 & TiGrowth & Porous Vacuum Plasma Spray \\
\hline
\end{tabular}




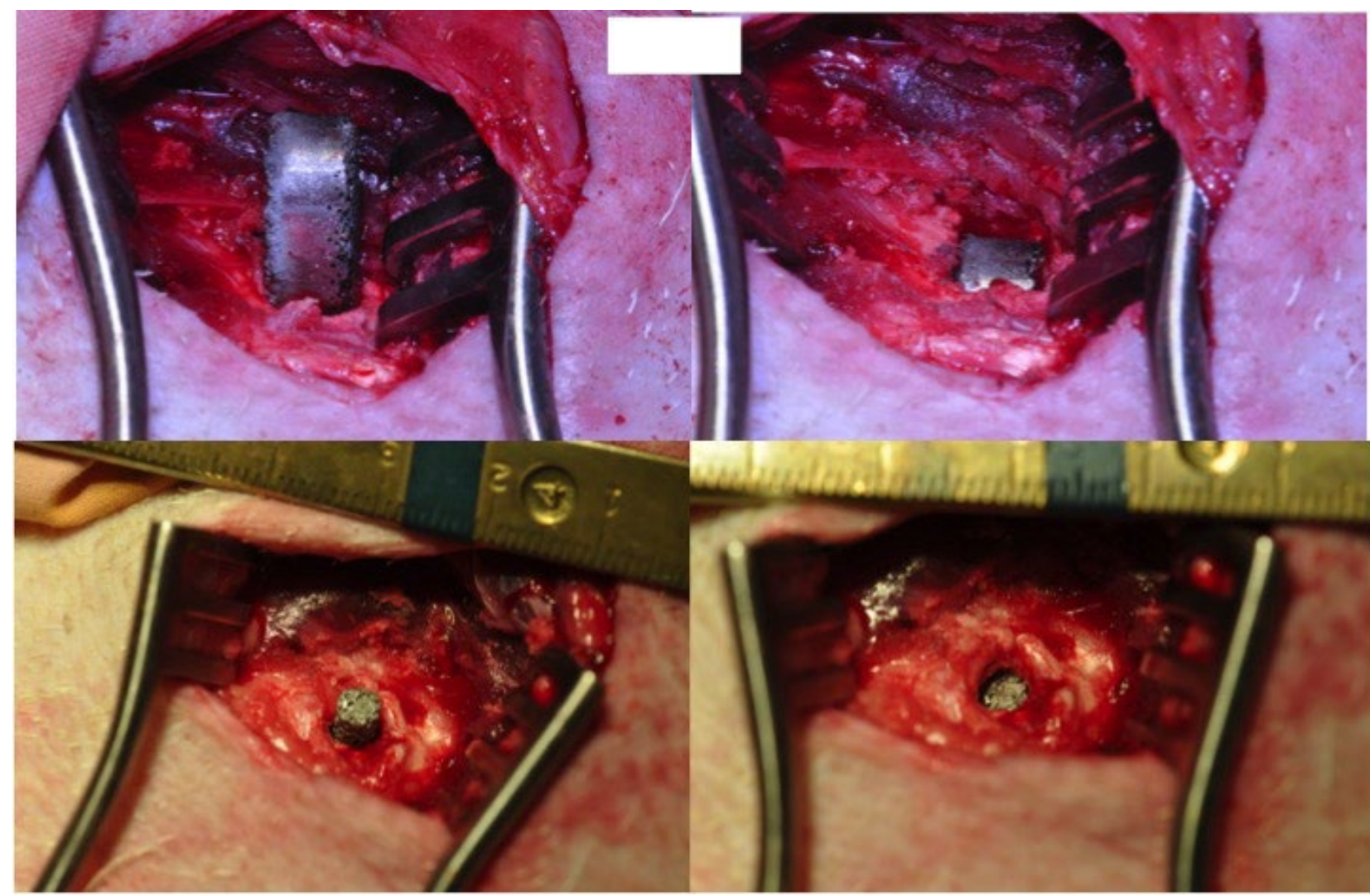

Fig. 3. Placement of the block (top pictures) and rod (bottom pictures) implants in the femoral condyle of sheep.

Block implants were inserted into $6 \times 8 \times 15 \mathrm{~mm}$ holes made bilaterally and proximally to the rod $(2$ different block implants per animal). For this implant, we first drilled a hole (drill bit $\varnothing=6 \mathrm{~mm}$ ) and then we used a specially designed rectangular osteotome $(6 \times 8 \mathrm{~mm})$ to cut a precise rectangle. The implants were then inserted in a press fit manner (Fig. 3). Therefore, one rod and one block implant were placed in each distal femoral medial condyle. For each kind of implant, sheep were sacrificed and specimens retrieved at 2 postoperative endpoints: $28 \pm 2 \mathrm{~d}(n=6$, for each implant), or $56 \pm 2 \mathrm{~d}(n=6$, for each implant). These two time points are referred to in the text as 4 and 8 weeks, respectively.

Immediately after the surgery, the joints were radiographed (HFX90V, brand Veterinary X-rays, Princes Risborough, Buckinghamshire, UK; FCR Prima II, Brand Fujifilm, St Martins Way, Bedfordshire, UK) as reassurance of the correct positioning of implants in cancellous bone (Fig. 4).

Perioperative antibiotic prophylaxis was given in the form of intramuscular Cefalexin $\left(\right.$ Ceporex $^{\circledR}$, GSK, Brentford, Middlesex, UK) preoperatively and every $12 \mathrm{~h}$ post-operatively for $3 \mathrm{~d}$. Post-operative analgesia was maintained by two $75 \mathrm{mg}$ Fentanyl transdermal patches (Duragesic $^{\circledR}$, Janssen Pharmaceuticals, NJ, USA), the first two patches were placed $12 \mathrm{~h}$ pre-operatively and the other two patches were placed $60 \mathrm{~h}$ after the first application.

Sheep were free to mobilise in their pen and weightbear fully. Bone blocks containing implants were retrieved at harvest, radiographed and processed for mechanical test (rods), histology and histomorphometry (blocks). Radiographs were analysed to search for peri-implant defects or radiolucent regions that could indicate osteolysis and to guide through the creation of slices for push-out test.

\section{Sections of bone for histology and push out test}

After 4 or 8 weeks in vivo, the implant and surrounding tissue were removed and immediately placed in $0.9 \%$ saline solution for a maximum of $3 \mathrm{~h}$. Based on radiographic images, the condyles and implant specimens were sectioned as shown in Fig. 5. The rod implants, intended to be used for mechanical test, were carefully sawn perpendicularly. The section for histology was placed in $10 \%$ formaldehyde solution for three days.

\section{Mechanical push-out test}

Specimens were tested at a rate of $5 \mathrm{~mm} / \mathrm{min}$, with a preload of $5 \mathrm{~N}$ at $5 \mathrm{~mm} / \mathrm{min}$ on a Zwick-Roell Z005 mechanical test instrument (Zwick GmbH \& Co., Ulm, Germany). A total of six implants/treatment were used to evaluate interfacial strength. The slabs, cut for push-out testing, were measured accurately for thickness. They were then mounted over a jig, which supported only the surrounding bone and not the implant, in a materials testing machine. A $4 \mathrm{~mm}$ diameter indenter was used to apply load to the implant (Fig. 6). The maximum load at which the implant was pushed out of the specimen was recorded (push-out force) in N. This value was used to define mechanical strength of the bone-implant interface. Differences between different groups of implants were considered statistically significant if $p<0.05$. 


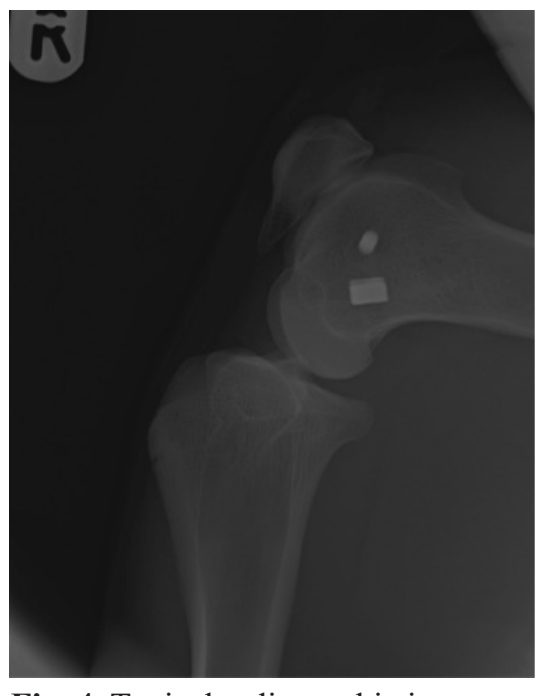

Fig. 4. Typical radiographic image on the surgery day $(\mathrm{S} 0)$.

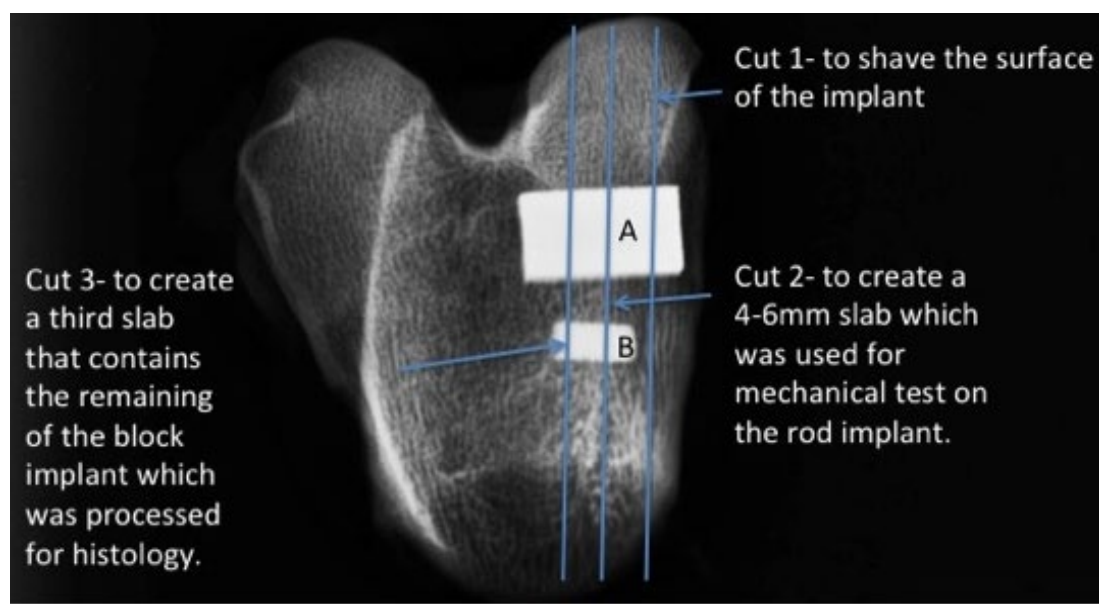

Fig. 5. Schematic of sectioning of femoral condyle and implant for histology and push out tests.

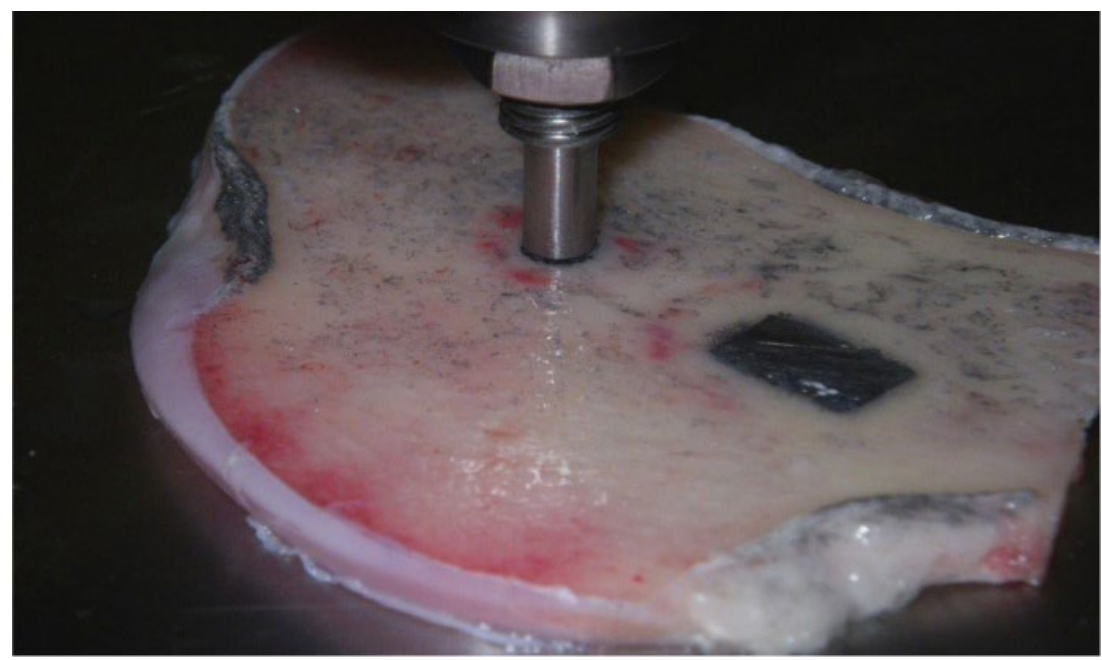

Fig. 6. Representative image of push-out test.

\section{Histology}

The sections created by cut 2 and 3 (Fig. 5) were prepared for undecalcified histology. The sections were fixed in $10 \%$ buffered formal saline ( $\mathrm{pH}$ 7.2). Following dehydration in alcohol and defatting in chloroform, specimens were embedded in hard-grade acrylic resin (LR White; London Resin Company, Reading, United Kingdom).

A longitudinal parallel thin section $(60 \mu \mathrm{m}$ thick $)$, including each block implant, was prepared using the Exakt micro-grinding system (Exakt-Apparalebau, Norderstedt, Germany) and polished on a Motopol 2000 (Bueler, Coventry, United Kingdom). Prior to histomorphometric analysis, the sections were stained with toluidine blue (Bennett and Radimska, 1966) for 20 min, which stains fibrous tissue blue, and Paragon (Martin et al., 1966) for 20 min, which stains new bone bright pink (to distinguish between newly formed and existing bone). For each sample, we created one $60 \mu \mathrm{m}$ slice. An additional thinner section ( $30 \mu \mathrm{m}$ thick) was cut for each sample and stained with haematoxylin and eosin stain (HE) to better distinguish the cells components.
Each slice was analysed blinded in random order. Images in a longitudinal direction (i.e., imaging the surface of the implant from end to end) were made. Each image was captured with use of a $2.5 \times$ objective lens and analysed with use of image analysis software (AxioVision 4.5; Carl Zeiss, Jena, Germany). The line intersection method was used to quantify bone implant contact length (BIC) with the exterior of the implant, and of bone ingrowth (BI) in the interior of the implant. Differences in the $\%$ BIC and $\mathrm{BI}$ between implants from the different treatment groups were compared. Differences were considered statistically significant if $p<0.05$.

\section{Scanning electron microscopy (SEM) and energy dispersive $x$-ray analysis (EDX)}

Scanning electron microscopy (SEM) and energy dispersive X-ray (EDX) analyses were performed on the same slides as used for histomorphometry. We analysed the bone-implant integration and presence, or not, of metal release in the surrounding bone (JSM-35C; JEOL, Welwyn Garden City, United Kingdom). The sections, embedded in 


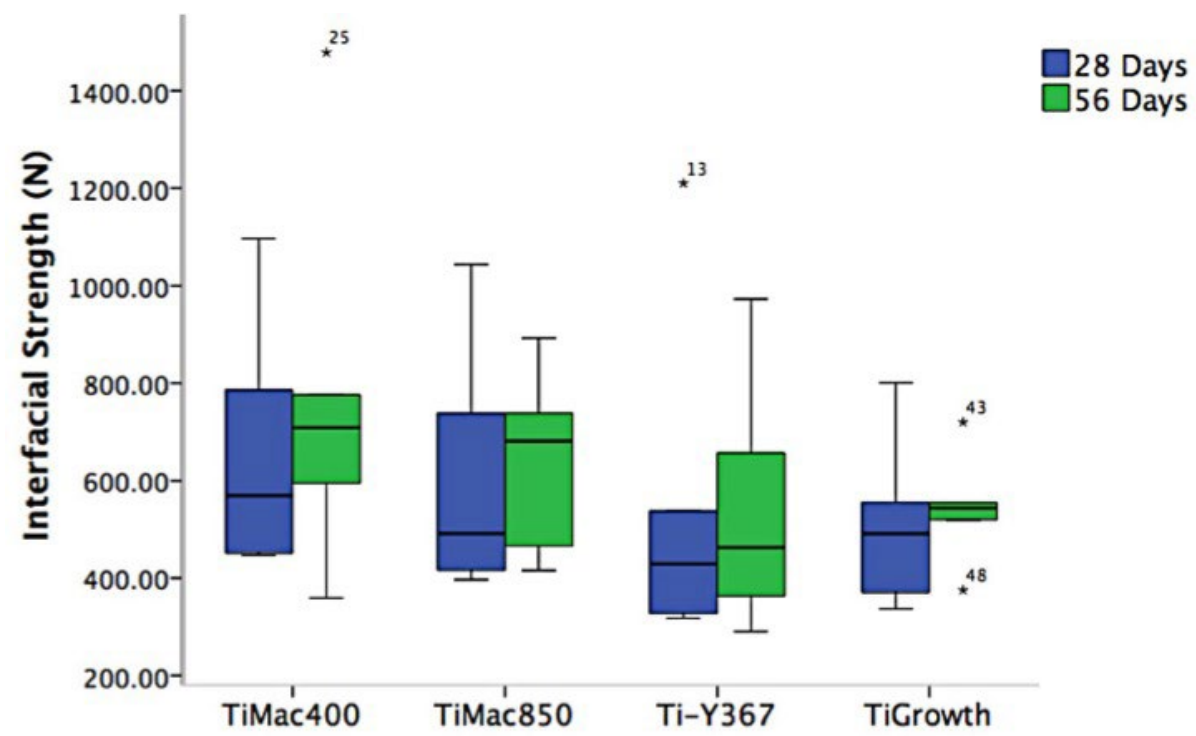

Fig. 7. Box plots for rod implant interfacial strength data, at 4 and 8 weeks. The bottom and top of the box are the first and third quartiles, and the band inside the box is the second quartile (the median). The lines extending vertically from the boxes (whiskers) indicate the minimum and maximum of all of the data. Outliers are plotted as individual points.

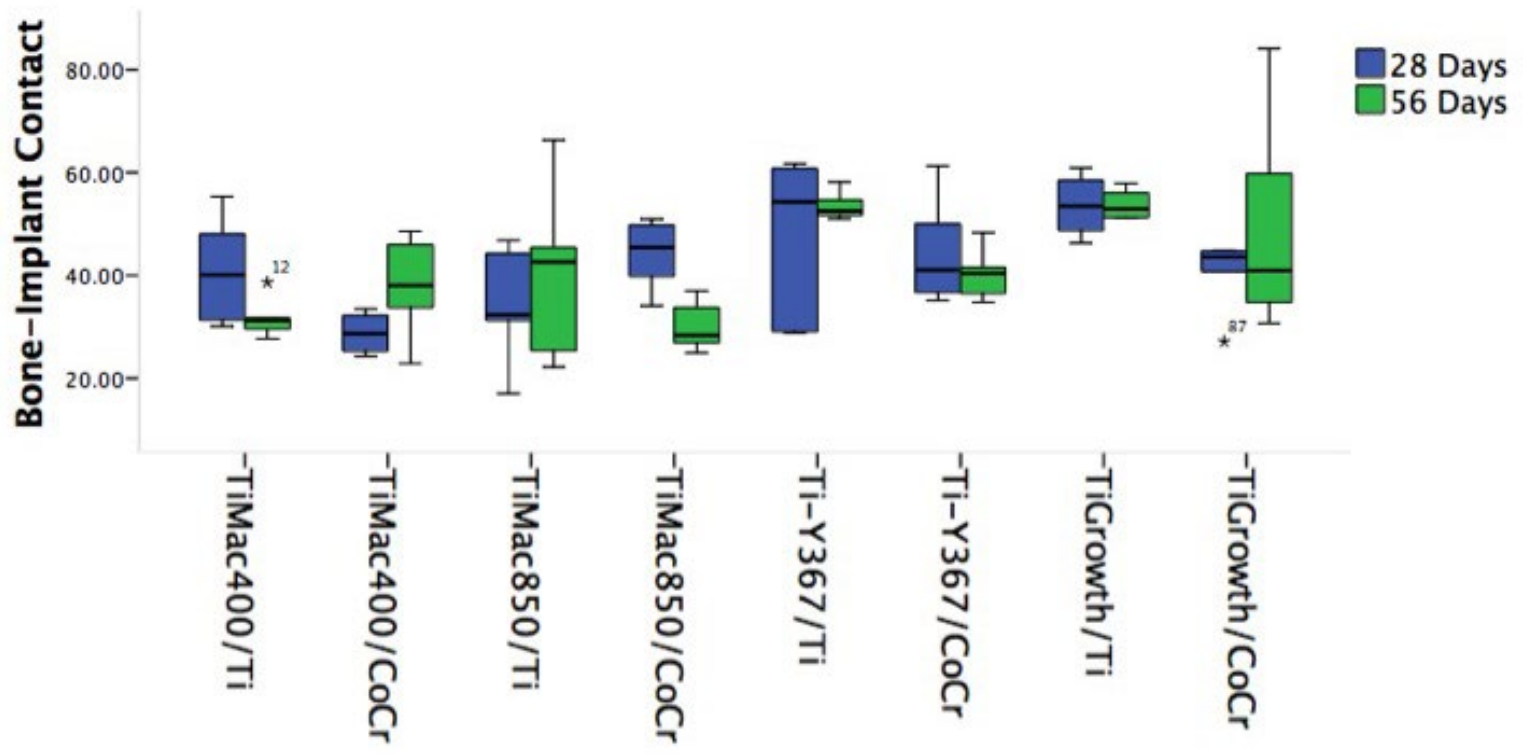

Fig. 8. Box plots for bone-implant contact $(\mathrm{BC})$ to the surfaces tested at both time-points: 4 weeks and 8 weeks. The bottom and top of the box are the first and third quartiles, and the band inside the box is the second quartile (the median). The lines extending vertically from the boxes (whiskers) indicate the minimum and maximum of all of the data. Outliers are plotted as individual points.

resin, were polished and sputter coated with argon (K550, Emi- Tech Ltd, Ashford, UK) before being observed in the SEM (JEOL JSM 5500 LV). Elemental maps of the implant and surrounding bone, and atomic metal content on surrounding bone were examined by EDX.

\section{Statistical analysis}

Both mechanical (push-out test) and histological (bone ingrowth and bone-implant contact) results were analysed using the SPSS version 22.0 statistical software (SPSS Inc., Chicago, Illinois). A Kolmogorov-Smirnov test showed that all data were non-parametric, and a Mann-Whitney U test was used to compare results obtained in the different experimental groups. A $p$-value $<0.05$ was considered significant.

\section{Results}

The sheep all recovered without complications and, after a period of approximately $7 \mathrm{~d}$, showed no signs of lameness and were fully weight-bearing. No significant swelling or inflammation was seen at the wound sites. There were no surgical or post-operative complications, indications 


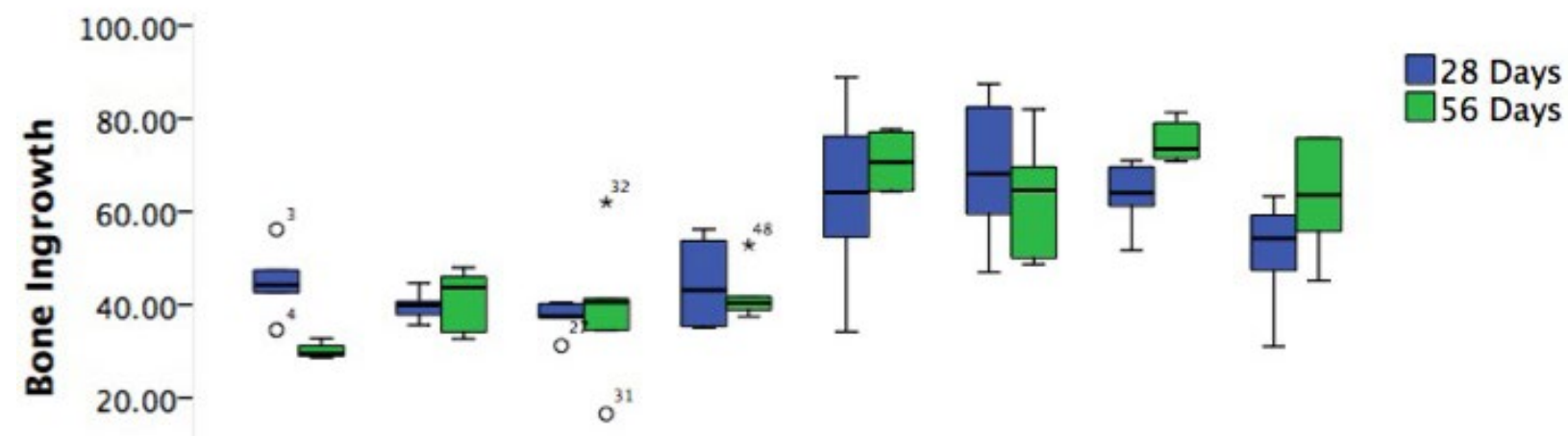

$.00-$
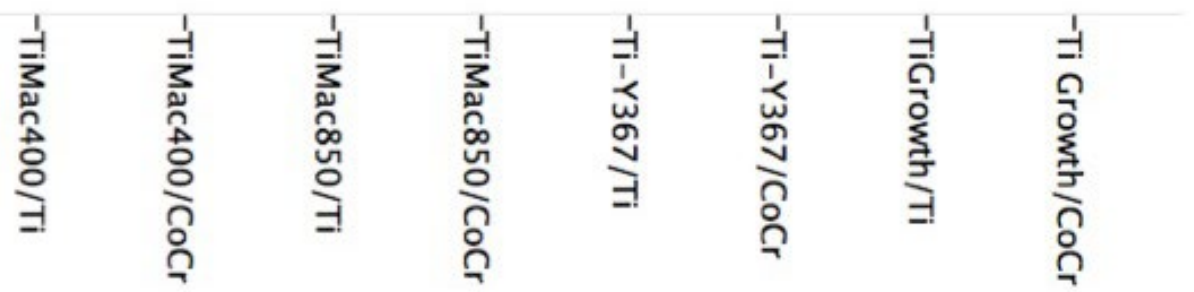

Fig. 9. Box plots for bone ingrowth (BI) to the surfaces tested at both time-points: 4 weeks and 8 weeks. The bottom and top of the box are the first and third quartiles, and the band inside the box is the second quartile (the median). The lines extending vertically from the boxes (whiskers) indicate the minimum and maximum of all of the data. Outliers are plotted as individual points.

of infection or abnormal tissue response at the time of retrieval. High-resolution radiographs of the implants in situ were obtained immediately after retrieval and all implants appeared to be stable with no peri-implant defects or radiolucent regions.

\section{Mechanical push-out test}

No significant difference was found in interfacial shearstrength between the four surfaces at each time point $(p>0.05)$. The different surfaces had no adverse effect on implant fixation in the cortical sites up to 8 weeks postoperatively. Interfacial strength increased, but not significant statistically, with time for all implant types at the time points used in this study $(p<0.05)$ (Fig. 7). Although not statistically significant, the interfacial strength increased more in the macroporous coatings (TiMac400 and TiMac850).

\section{Bone-implant contact (BIC)}

The results demonstrated comparable amounts of bone contact within all the implants.

Significantly more bone was formed in the plasma spray surfaces than in the porous surface (Fig. 8). Bone ingrowth was evident within all 48 implants.

The best histomorphometric results, in terms of boneimplant contact (BIC), were found for two plasma spray surfaces, the Ti-Y367/Ti $(48.2 \pm 2.8 \%$ at 4 weeks and $53.4 \pm 1.1 \%$ at 8 weeks) and TiGrowth/Ti $(53.6 \pm 2.4 \%$ at 4 weeks and $53.7 \pm 1.1 \%$ at 8 weeks). No significant differences in $\mathrm{BC}$ were seen between 8 and 4 weeks of implantation, less in the TiMac850/CoCr $(44.3 \pm 2.6 \%$ at 4 weeks and $29.9 \pm 1.9$ at 8 weeks) that showed a significant decrease of bone contact at 8 weeks. Among the macroporous surfaces, the TiMac400/CoCr $(37.9 \pm 3.9 \%)$ and $\mathrm{TiMac} 850 / \mathrm{Ti}(40.7 \pm 6.5)$ showed a better performance than TiMac850/CoCr $(29.9 \pm 1.9 \%)$ and TiMac400/Ti $(31.6 \pm 1.5 \%)$ after 8 weeks of loading.

\section{Bone ingrowth (BI)}

The results demonstrated comparable area of colonisation (bone ingrowth within implant surface) by bone of the porous coatings within all the implants. Significantly greater percentage of bone had grown in the plasma spray surfaces than in the porous surface. Bone growth was evident within all 48 implants.

The highest levels of bone-ingrowth were found for plasma spray surfaces, mainly the TiGrowth/Ti. These showed a greater level in week $4(74.9 \pm 1.8 \%)$ than in week $8(63.6 \pm 2.8 \%$ ) (Fig. 9). No significant differences in bone-ingrowth were seen between 4 and 8 weeks of implantation for the porous surfaces, and less in the TiMac400/Ti that showed a significant decrease of boneingrowth at 8 weeks. Among the porous surfaces, few significant differences were found. The TiMac850/CoCr $(41.9 \pm 2.3 \%)$ and $\mathrm{TiMac} 400 / \mathrm{CoCr}(41.4 \pm 2.6 \%)$ showed a better performance than TiMac400/Ti $(30.1 \pm 0.7 \%)$ at 8 weeks.

\section{Histological evaluation of implants}

Four weeks after implant placement, new bone filled the interfacial zone around the implants, with new bone growing on pre-existing bone and into the implant 


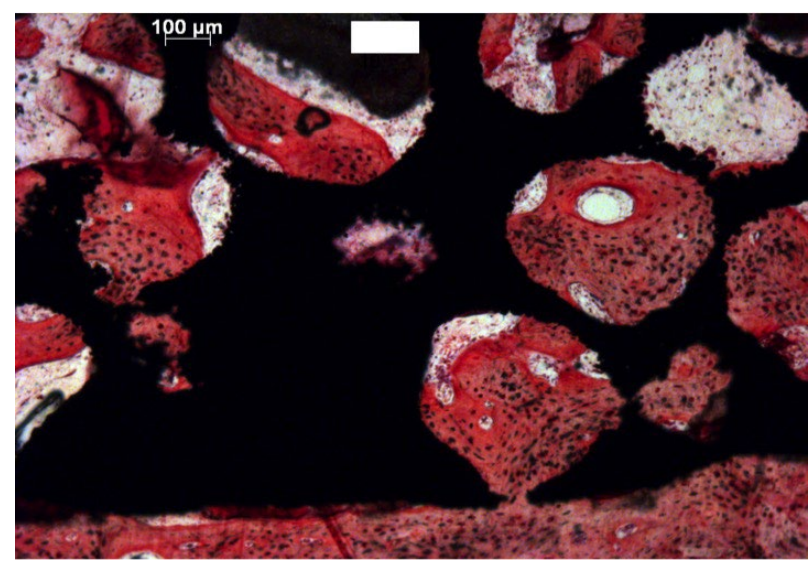

Fig. 10. Newly formed bone on implant surface and inside porous with osteocytes.

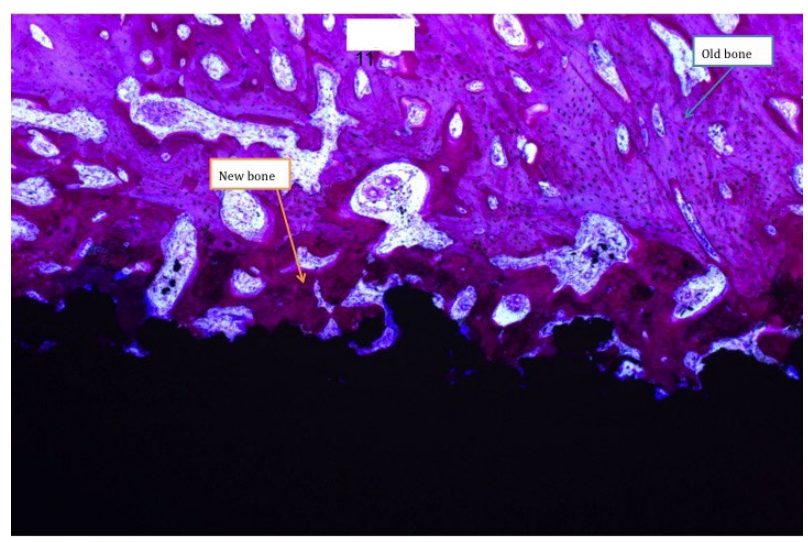

Fig. 11. New-formed bone in direct contact with implant plasma surface (deeper pink staining). Old bone stains paler pink with Paragon staining. Some technique artefacts can be seen as loose black particles.

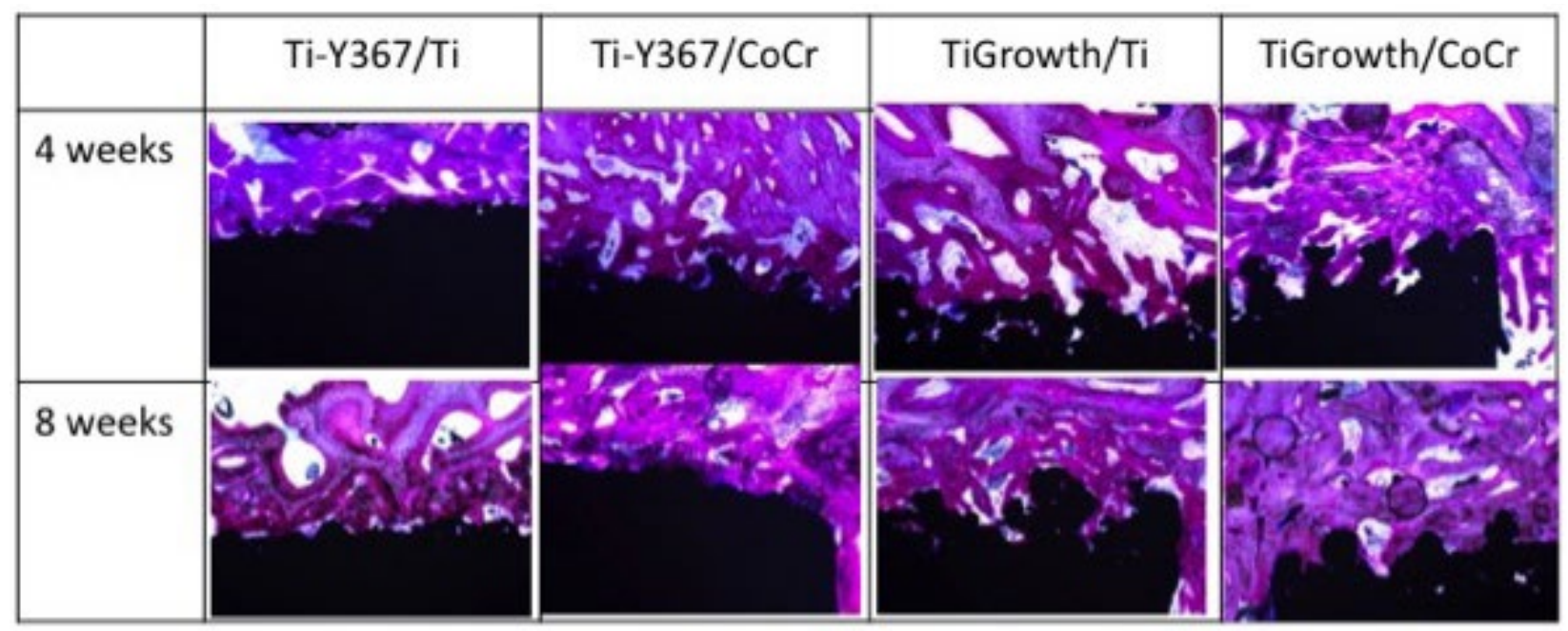

Fig. 12. Representative light microscopy images of control implants (TiGrowth/Ti, TiGrowth/CoCr, Ti-Y367/Ti, and Ti-Y367/Cocr) at 4 and 8 weeks after implantation.

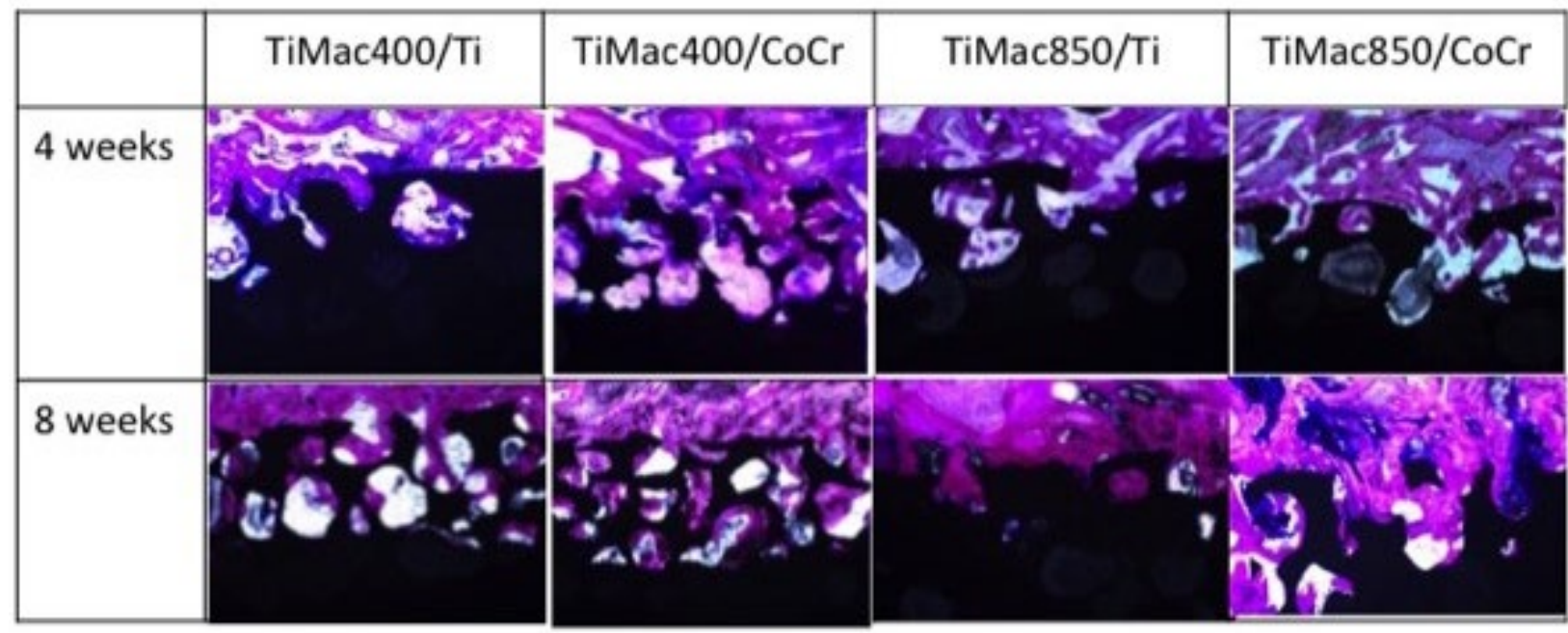

Fig. 13. Representative light microscopy images of macroporous implants (TiMac400/Ti, TiMac400/CoCr, TiMac850/ Ti, and TiMac850/Cocr) at 4 and 8 weeks after implantation. 


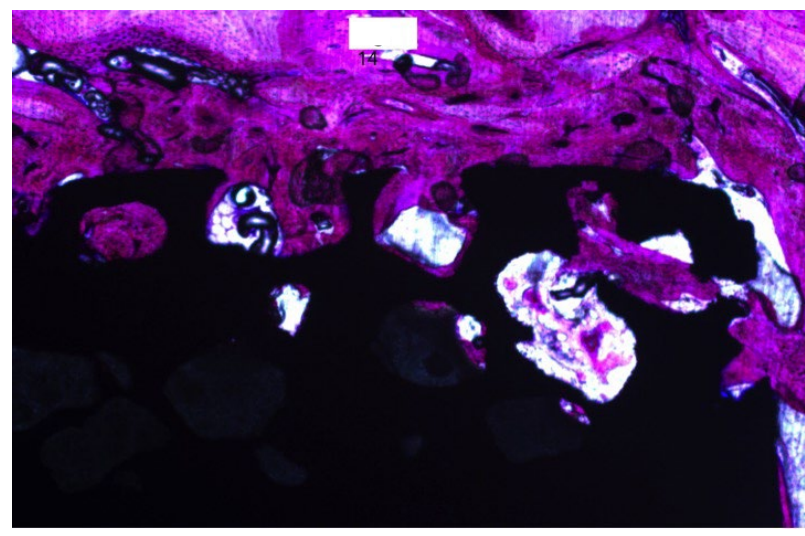

Fig. 14. Bone formation evident within the pores, especially the more superficial pores of the porous surface at 8 weeks but also evident in deeper porosities.

grooves in direct contact with the implant surface. All the coatings remained adherent to the substrates 4 weeks after implantation.

The histologic findings demonstrated that all samples were correctly implanted in the cancellous bone of femoral condyles. No inflammatory infiltration consisting of mononuclear, neutrophils or eosinophils was observed, nor was there an osteoclastic reaction in the vicinity of the implant. Osteoblasts could be seen on newly formed bone directly on the porous implant surface (Fig. 10).

Histological analysis of specimens in all groups demonstrated abundant bone growth and direct contact for all the surfaces. The Paragon stain showed the new bone as a deep pink colour in the histology images, indicating newly formed bone growing directly on the implant surface (Fig. 11).

The presence of inflammatory cells was not observed in any of the surfaces. Additional thinner sections were used to confirm that the cells were osteocytes and not inflammatory cells. The high density of osteocytes is normal in rapid growing new bone.

Representative images of controls implants, TiGrowth and Ti-Y367, are shown in Fig. 12. Both surfaces showed tight adhesion of bone to the implant.

Representative images of macroporous implants, TiMac400 and TiMac850, are shown in Fig. 13.

In both macroporous surfaces, direct integration of the bone and penetration into the pores and the structure of the implant were observed. Substantially more bone could be observed within the pores at 8 weeks compared with 4 weeks (Fig. 14). Also, substantial ingrowth of new bone was observed deep through the residual HA inside the pores (Fig. 15).

\section{SEM and EDX}

SEM analysis of specimens in all groups demonstrated abundant bone ingrowth within the implant and direct contact of bone and implant in all the surfaces. A substantial ingrowth of new bone was observed deep through the hydroxyapatite inside the porous structure (Fig. 16). No
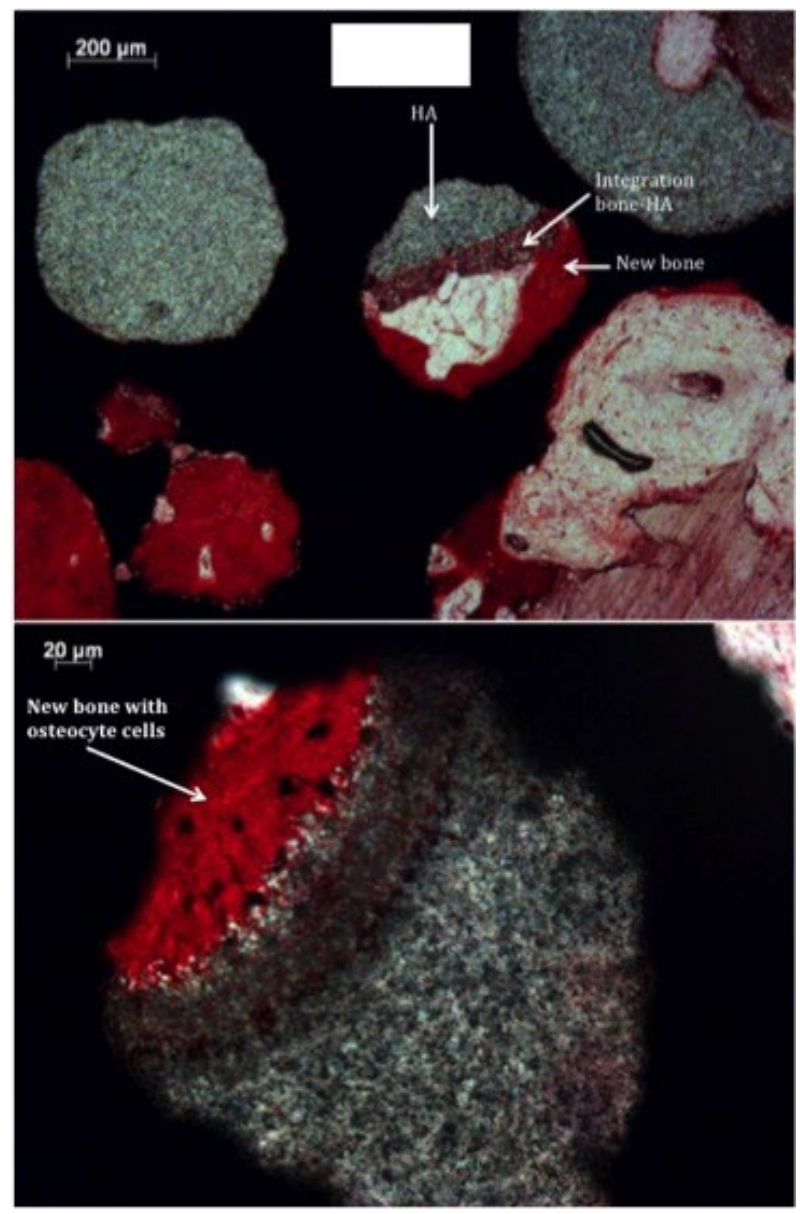

Fig. 15. Bone (red)-hydroxyapatite (HA) (grey) integration in the macroporous surface. In the high magnification (below), bone can be seen growing deep through HA crystals, reaching the bottom of the porous.

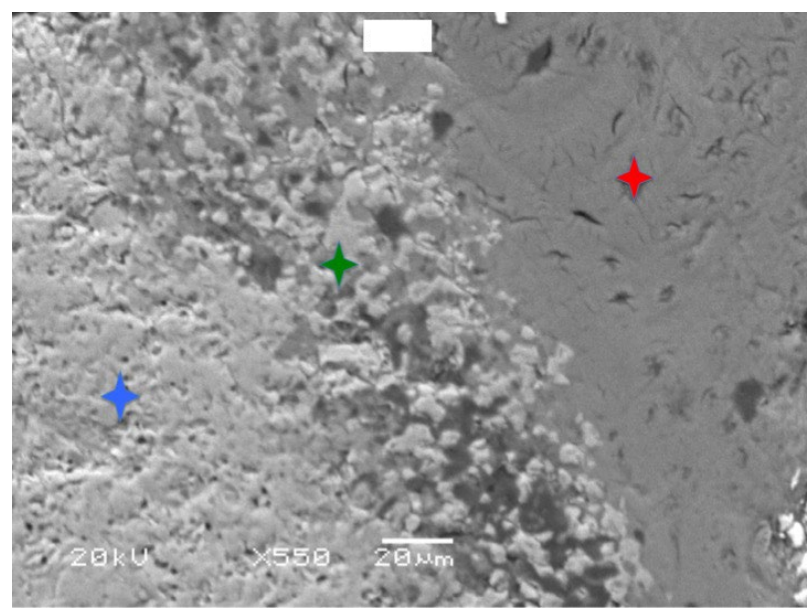

Fig. 16. Bone (red star)-hydroxyapatite (HA) (blue star) integration (green star) in the macroporous surface. Bone can be seen growing deep through HA crystals.

evidence of metal ions was found in the surrounding bone and soft tissue in any group, in the EDX analysis, confirming that there was no release of metal from the implant to surrounding bone. 


\section{Discussion}

Fast plasma sintering technology produced implants with strongly connected macroporous surfaces. In this study, we used two controls: TiGrowth and air plasma spray (Ti-Y367). Both controls were selected as these coatings are already commercially available and clinically used. FPS is suitable for manufacturing devices which combine different materials all together in a unique solid piece (i.e. functionally graded devices - FGD). Furthermore, FPS allows for having, at the same time, materials (e.g. titanium) in two different density status: fully dense and highly porous in different parts of the piece (i.e. functionally graded material - FGM).

All the implant groups integrated well with surrounding bone, as shown by the direct formation of new bone on the implant surfaces and the lack of inflammatory or foreign body reaction.

Primary fixation is one of the most important factors in establishing adequate osseointegration between bone and an implant fixture (Johansson and Albrektsson, 1987). As such, plasma spraying of HA and titanium plasma spray (TPS) coatings has been employed to maximise bone formation and rapid stabilisation. It has been recognised that plasma spraying can also produce highly porous titanium surfaces with open and interconnected pores, which can vastly improve bone ingrowth characteristics (el-Ghannam et al., 1995). In our study, we could observe an important primary fixation of the implants for all the coatings. Furthermore, as loading is an important factor for early bone growth, our model proved to be a good model, even if it was a partially loaded model.

The interfacial strength observed in the present study for TiMac400 and TiMac850 was not significantly different from the TiGrowth and Ti-Y367 at 4 or 8 weeks after implant placement, suggesting that macroporous implants coatings are beneficial for the initial healing period showing rapid effective osseointegration. Earlier time points may be useful in further studies to optimise the surface types. Even at the four-week point, all surfaces were well integrated with host tissue.

Although it has not been statistically significant, the interfacial strength for the TiMac400 and TiMac850 showed a tendency to increase over the time. On other hand, it remained quite stable for the TiGrowth and TiY367 surfaces.

Biemond et al. (2011b) investigated a porous E-beam structure, combined with two biomimetic CaP coatings, and found differences in the push-out tests between 3 and 15 weeks. However, when we compared our push-out results with theirs, we could observe that our implants performed much better than theirs - even when comparing ours at 8 weeks with theirs at 15 weeks. This is probably explained by the fact that Biemond et al. (2011b) used a non-loaded model. It is well known that for early bone ingrowth (and its acceleration), load bearing is an important factor.

Energy dispersive X-ray (EDX) analysis showed no evidence of metal contamination in the surrounding tissues. The technique allowed valid identification of the different metal constructs. SEM/EDX of implants also indicated that no failure had occurred at the coating-substrate interface and/or within the coating, confirming successful coatingsubstrate adhesion as well as the properties of the specific coatings.

Histological findings indicated statistical differences in $\%$ bone contact length between the TiMac400/CoCr, TiMac400/Ti, TiMac850/CoCr and TiMac850/Ti implant groups at 8 weeks after implant placement. In addition, best results in contact length of Ti-Y367/Ti and TiGrowth/ Ti implant groups were also observed.

Other studies have also indicated a higher \% bone contact lengths for plasma-sprayed implants $90 \mathrm{~d}$ after implant placement (Novaes et al., 2002; Ong et al., 2004).

Significantly greater percentage of bone has grown in the TiGrowth and Ti-Y367 surfaces than in the macroporous surface. However, further bone area colonisation in the plasma spray surface is limited by the absence of depth in these. On other hand, TiMac400 and TiMac850 showed a good bone colonisation of the implant and potential for further bone ingrowth.

The histological observation made in this study indicated different mechanisms for achieving high bone-implant contact, when comparing controls and macroporous implants. The Ti-Y367 and TiGrowth surfaces allow an earlier bone contact and ingrowth. Therefore, those are limited by the shallow and limited surface availability those implants present. On other hand, the macroporous implants (TiMac400 and TiMac850) have greater depths of porosity space to allow further depth bone ingrowth. Also, the porous surfaces are deeper than the plasma spray surfaces. Therefore, it would take longer to have good proportional bone area colonisation within these surfaces. Furthermore, bone ingrowth depth is restricted by pore depth and measuring direct bone-implant contact is the only method which enables comparison of porous and solid specimens (Biemond et al., 2011a).

The amount of direct bone-implant contact the TiMac400 and TiMac850 produced appeared to be comparable to the control coatings. Hence, the new surface structures have the potential to be successful surface structures for orthopaedic implants.

Although it is clear that pore size affects bone ingrowth, the optimal pore size has yet to be determined. There appears to be an optimal pore size for bone ingrowth. A review study on implant fixation by bone ingrowth indicated the optimum size for bone ingrowth in the range of 100-400 $\mu \mathrm{m}$ (Kienapfel et al., 1999). This would go against the pore sizes chosen in this study. However, more recent studies showed that larger pores allow bone ingrowth to occur (Frosch et al., 2004; Hollister et al., 2005). Due to the wide variety of material and pores shapes and sizes, the optimum range might be different for each particular structure, requiring in vivo testing of each combination (Tarala et al., 2011). Bobyn et al. (1999) showed that the extent of ingrowth of implants with pores of $710 \mu \mathrm{m}$ was significantly greater compared to those with pores of $550 \mu \mathrm{m}$ at 4 and 16 weeks after implantation. This indicates that $400 \mu \mathrm{m}$ is not the maximum pore size to enhance bone ingrowth. In our study, this could be seen only for the TiMac850 surface, which presented a better 
BIC than TiMac400 at 8 weeks. And, in contrast to the observations of Bobyn et al. (1999) on TiMac400 and TiMac850, our study showed a quite similar ingrowth.

One disadvantage of a larger pore size and a higher porosity is the length of time it takes for full integration of bone into the implant (Biemond et al., 2011a). We could conclude that the results of our study show that the ultimate bone ingrowth may not be accomplished for the TiMac structures in the 8 -week study period. Bone ingrowth is likely to continue after the 8 -week study period and will further anchor the implant to the bone. However, one can expect that ingrowth beyond a certain depth does not enhance the strength of the bone-implant interface, similar to that seen for the cement-bone interface (Biemond et al., 2011a, Tarala et al., 2011).

The fact that, in this study, the amount of bone did not increase over the time may also indicate that earlier and later time points assessment may be useful in further studies to compare the surfaces on other integration stages.

As in other studies (Biemond et al., 2011b), we used three different methods to assess bone ingrowth potential. A push-out test for mechanical evaluation of the boneimplant interface and two methods for histological analysis (bone ingrowth (BI) and bone implant contact (BIC)). Both histological methods have a different focus and it is difficult to say which one best defines bone ingrowth. Therefore, these two methods become more valuable when compared with the results of the push-out test that represents the actual mechanical strength at the bone-implant interface (Biemond et al., 2011b). In our study, there was no agreement between the BIC and BI measurements and the push-out test. Moriyama et al. (2010) and Biemond et al. (2011a) suggest that histology assessment is not a good method to assess the effect of bone ingrowth on mechanical strength. Correlation between bone ingrowth depth and mechanical strength of the bone-implant interface is likely to be influenced by the fact that ingrowth beyond a certain depth does not enhance the strength of the boneimplant interface, similar to that seen for the cement-bone interface (Biemond et al., 2011b). The fact that, in our study, macroporous surfaces performed similarly to the clinically used surfaces at the push out test - even having a lower bone ingrowth, may indicate that the macroporous surface has a better attachment with bone, even in low bone presence.

Our results also show that the different metal substrates (Ti or $\mathrm{CoCr}$ ) did not affect or delay bone colonisation inside the applied porous surface structures.

FPS technology produced implants with macroporous surfaces strongly connected with 2 different fully dense substrate bulks. These specimens were obtained in one single manufacturing step and with only a few minutes to process. Results in this partially loaded in vivo model confirmed that FPS made devices can reach an osseointegration level that is not different from implants made with state of the art technology and with long term successful clinical history.

FPS is a relatively novel powder metallurgy process. It comprises prepacking powders inside a mould, positioning the mould in a working chamber, and then applying, at the same time, high pressure and temperature and using a current flow through the mould and the powder materials as heating source (i.e. Joule effect). The process is rapid, as in few minutes the powders are transformed in a solid mass in a nearly net shape, close to that desired for the final object (Tokita et al., 1993; Munir et al., 2006). This capability makes the process economically competitive against conventional sintering processes. However, the specific temperature profile applied during the process (i.e. very fast heating rate, short periods at maximum temperature, and relatively lower than conventional sintering temperatures) enables the process to release well-known alloys in a very fine microstructure (Omori et al., 2000; Menapace et al., 2013). Moreover, the capability of this sintering process to produce a localised field of overheating inside the mould allows the combination of different materials together with very strong interfacial connection (i.e. functionally graded components). In the present work, a sintering temperature of $1,000{ }^{\circ} \mathrm{C}$ was applied, at a pressure of $40 \mathrm{MPa}$ and a process time of 5 min to obtain bimetallic cylinders made of a fully dense ASTM F75 cobalt alloy layer bonded to a macroporous $\mathrm{CP}$ Ti layer. The intermetallic transition layer was found to be $200 \mu \mathrm{m}$ in thickness (Vicente et al., 2013).

The plasma-spray process uses inert gases (argonnitrogen) that flow over a cylindrical copper anode and a tungsten cathode while a direct current arc is maintained, which produces the gas plasma where the core temperature can be as high as $30,000{ }^{\circ} \mathrm{C}$. Powder metals or ceramics are injected into the plasma stream. The material is essentially melted in the plasma while being accelerated by the high-velocity plasma-gas stream. The semi-molten droplets attach to the previously roughened substrate target surface forming splats of particles one after another. The entire process is controlled so as not to apply or transfer excessive energy, specifically heat, to the substrate (Web ref. 4). Thermal plasma spray is a relatively well-known technology in use in the medical field, to obtain roughporous titanium coating, for over thirty years. If the process is run at atmospheric conditions it is called air plasma spray (APS), and under vacuum it is vacuum plasma spray (VPS). VPS allows application of porous coatings, whereas APS does not.

The capability of FPS to merge similar (i.e. CP Ti and Ti Alloy) or different materials (i.e. CP Ti and CoCrMo alloy), both in fully dense and in highly porous status, opens new opportunities for designers to conceive complex implantable devices with multiple features. FPS productivity may sustain large serial production.

Some limitations of the present study should be acknowledged. First of all, no fluorochrome labelling was performed. Second, we should have performed an earlier time point assessment. With such information, we might had found differences in the coatings related to the speed of bone ingrowth and mechanical strength.

\section{Conclusion}

This study indicated a significantly higher bone contact length for TiGrowth and Ti-Y367 implants as compared to TiMac400 and TiMac850 implants for both periods tested 
(4 weeks and 8 weeks after implantation) in normal bone. On the other hand, TiMac400 and TiMac850 surfaces showed larger size interconnected porosity, thus allowing for deeper bone ingrowth and better osseointegration.

However, despite these differences in morphological aspects and histomorphometric results, the push-out test at the time points used gave similar values of strength to specimens obtained with conventional technology (i.e. plasma spray over casted and turned fully dense bulk) and innovative technology (i.e. FPS), thus suggesting same capability for both the processes to deliver implants capable of reaching fixation both at early ( 4 weeks) and mid-term ( 8 weeks) observation times.

In conclusion, the newly developed surfaces, TiMac400 and Timac850, provide sufficient integration at the boneimplant surface thus achieving mechanical stability. The bone ingrowth into these new surfaces appears to be comparable to the clinically successful surfaces, TiGrowth and Ti-Y367, at 4 and 8 weeks after implantation.

This result is considered promising to support further investigations of this novel technology, as an example of using more complex animal models with loaded implants and a shorter observation time.

\section{Acknowledgements}

The authors wish to thank Emanuele Magalini and Eleonora Preve (Eurocoating spa) for providing the implants for this study. This study is part of SpaceCups Project cosponsored by Provincia Autonoma Trento, Italy.

\section{References}

Baril E, Lefebvre LP, Hacking SA (2011) Direct visualization and quantification of bone growth into porous titanium implants using micro computed tomography. J Mater Sci Mater Med 22: 1321-1332.

Bennett D, Radimska O (1966) Flotation-fluid staining; toluidine blue applied to maraglas sections. Stain Technol 41:349-350.

Biemond JE, Aquarius R, Verdonschot N, Buma P (2011a) Frictional and bone ingrowth properties of engineered surface topographies produced by E-beam technology. Arch Orthop Trauma Surg 131:711-718.

Biemond JE, Eufrasio TS, Hannink G, Verdonschot N, Buma P (2011b) Assesment of bone ingrowth potential of biomimetic hydroxyapatite and brushite coated porous E-beam structures. J Mater Sci: Mater Med 22: 917-925.

Bobyn JD, Stackpool GJ, Hacking SA, Tanzer M, Krygier JJ (1999) Characteristics of bone ingrowth and interface mechanics of a new porous tantalum biomaterial. J Bone Joint Surg Br 81:907-914.

Chen D, Bertollo N, Lau A, Taki N, Nishino T, Mishima H, Kawamura H, Walsh WR (2011) Osseointegration of porous titanium implants with and without electrochemically deposited DCPD coating in an ovine model. J Orthop Surg Res 6: 56.

Della Valle CJ, Mesko NW, Quigley L, Rosenberg AG, Jacobs JJ, Galante JO (2009) Primary total hip arthroplasty with a porous-coated acetabular component. A concise follow-up, at a minimum of twenty years, of previous reports. J Bone Joint Surg Am 91: 1130-1135.

el-Ghannam A, Ducheyne P, Shapiro IM (1995) Bioactive material template for in vitro synthesis of bone. J Biomed Mater Res 29: 359-370.

Facchini L, Magalini E, Robotti P, Molinari A (2009) Microstructure and mechanical properties of Ti-6Al-4V produced by electron beam melting of pre-alloyed powders. Rapid Prototyping Journal 15/3: 171-178.

Frosch KH, Barvencik F, Viereck V, Lohmann CH, Dresing K, Breme J, Brunner E, Stürmer KM (2004) Growth behavior, matrix production, and gene expression of human osteoblasts in defined cylindrical titanium channels. J Biomed Mater Res A 68: 325-334.

Godoy RF, Blunn G, Goodship A (2012) In vivo evaluation of titanium macro-porous structures manufactured through an innovative powder metallurgy approaches. Eur Cell Mater 24 (Suppl 1): 44.

Hollister SJ, Lin CY, Saito E, Lin CY, Schek RD, Taboas JM, Williams JM, Partee B, Flanagan CL, Diggs A, Wilke EN, Van Lenthe GH, Müller R, Wirtz T, Das S, Feinberg SE, Krebsbach PH (2005) Engineering craniofacial scaffolds. Orthod Craniofac Res 8:162-173.

Johansson C, Albrektsson T (1987) Integration of screw implants in the rabbit: a 1-year follow-up of removal torque of titanium implants. Int J Oral Maxillofac Implants 2: 69-75.

Karageorgiou V, Kaplan D (2005) Porosity of 3D biomaterial scaffolds and osteogenesis. Biomaterials 26: 5474-5491.

Kienapfel H, Sprey C, Wilke A, Griss P (1999) Implant fixation by bone ingrowth. J Arthroplasty 14: 355-368.

Lefebvre LP, Baril E, Bureau MN (2009) Effect of the oxygen content in solution on the static and cyclic deformation of titanium foams. J Mater Sci Mater Med 20: 2223-2233.

Levine B, Della Valle CJ, Jacobs JJ (2006) Applications of porous tantalum in total hip arthroplasty. J Am Acad Orthop Surg 14: 646-655.

Martin JH, Lynn JA, Nickey WM (1966) A rapid polychrome stain for epoxy-embedded tissue. Am J Clin Pathol 46:250-251.

Matassi F, Botti A, Sirleo L, Carulli C, Innocenti M (2013) Porous metal for orthopedics implants. Clin Cases Miner Bone Metab. 10: 111-115.

Menapace C, Vicente N, Molinari A (2013) Hot forging of Ti-6Al-4V alloy preforms produced by spark plasma sintering of powders. Powder Metallurgy 56: 102-110.

Moriyama Y, Ayukawa Y, Ogino Y, Atsuta I, Todo M, Takao Y, Koyano K (2010) Local application of fluvastatin improves peri-implant bone quantity and mechanical properties: a rodent study. Acta Biomater 6: 1610-1618.

Munir ZA, Anselmi-Tamburini U, Ohyanagi M (2006) The effect of electric field and pressure on the synthesis and consolidation of materials: a review of the spark plasma sintering method. J Mater Sci 41: 763-777.

Muth J, Poggie M, Kulesha G, Meneghini RM (2013) Novel highly porous metal technology in artificial hip and knee replacement: processing methodologies and clinical applications. JOM 65: 318-325. 
Novaes Jr. AB, Souza SL, de Oliveira PT, Souza AM (2002) Histomorphometric analysis of the boneimplant contact obtained with 4 different implant surface treatments placed side by side in the dog mandible. Int $\mathrm{J}$ Oral Maxillofac Implants 17: 377-383.

Omori M (2000) Sintering, consolidation, reaction and crystal growth by the spark plasma system (SPS). Mater Sci Eng A 287: 183-188.

Ong JL, Carnes DL, Bessho K (2004) Evaluation of titanium plasma-sprayed and plasma-sprayed hydroxyapatite implants in vivo. Biomaterials 25: 46014606.

Otsuki B, Takemoto M, Fujibayashi S, Neo M, Kokubo T, Nakamura T (2006) Pore throat size and connectivity determine bone and tissue ingrowth into porous implants: three-dimensional micro-CT based structural analyses of porous bioactive titanium implants. Biomaterials 27: 5892-5900.

Ryan G, Pandit A, Apatsidis DP (2006) Fabrication methods of porous metals for use in orthopaedic applications. Biomaterials 27: 2651-2670.

Simmons CA, Meguid SA, Pilliar RM (2001) Differences in osseointegration rate due to implant surface geometry can be explained by local tissue strains. J Orthop Res 19: 187-194.

Takemoto M, Fujibayashi S, Neo M, Suzuki J, Matsushita T, Kokubo T, Nakamura T (2006) Osteoinductive porous titanium implants: effect of sodium removal by dilute $\mathrm{HCl}$ treatment. Biomaterials 27: 2682-2691.

Tarala M, Waanders D, Biemond JE, Hannink G, Janssen D, Buma P, Verdonschot N (2011) The effect of bone ingrowth depth on the tensile and shear strength of the implant-bone e-beam produced interface. J Mater Sci Mater Med 22: 2339-2346.

Tokita M (1993) Trends in advanced SPS spark plasma sintering systems and technology. J Soc Powder Tech Jpn 30: $790-804$.

Tsukeoka T, Suzuki M, Ohtsuki C, Tsuneizumi Y, Miyagi J, Sugino A, Inoue T, Michihiro R, Moriya H (2005) Enhanced fixation of implants by bone ingrowth to titanium fiber mesh: effect of incorporation of hydroxyapatite powder. J Biomed Mater Res B Appl Biomater 5: 168-176.

Vicente N, Fedrizzi A, Bazzanella N, Casari F, Buccioti F, Molinari A (2013) Microstructure of interface of SPS co-sintered and sinter bonded cp2-Ti and Co-28Cr-6Mo. Powder Metallurgy 56: 143-148.

\section{Web References}

1. Servizio Sanitario Regionale, ER. (2013) Interventi di protesi d'anca, di ginocchio e di spalla in Emilia Romagna. Annual Report. 1-109. https://ripo.cineca.it/pdf/ relazione_globale_2012.pdf [06-04-2016]

2. NJR (National Joint Registry for England, Wales and North Ireland) (2013) Prostheses used in hip, knee and ankle replacement procedures 2012. 10th Annual report 1-81. http://www.njrcentre.org.uk/njrcentre/ Portals/0/Documents/England/Reports/10th_annual_ report/NJR\%20Prostheses $\% 20$ used $\% 20$ in $\% 20$ hip, $\% 20$ knee, $\% 20$ ankle, $\% 20$ shoulder $\% 20$ and $\% 20$ elbow $\% 20$ replacements\%202012.pdf [06-04-2016]

3. Bucciotti F, Facchini L, Preve E, Robotti P (2013) Fast Powder Sintering a technological tool with high potential for joint prostheses development. Orthopedic Research Society Annual Meeting, San Francisco, USA. http://www.ors.org/Transactions/59/PS2--106/1854.html [06-04-2016]

4. Glass L, Robotti P (2011) Macromanagement: surface manufacturing for implants. http://www.orthotec. com/article/surface-manufacturing-implants [13-02-2014].

\section{Discussion with Reviewers}

Janet Henderson: The "inter-facial strength" assessed by mechanical push-out is dependent on both bone/ implant contact and bone ingrowth. There is a significant reduction in bone/implant contact in TiMac850/CoCr and reduced bone ingrowth in TiMac400/Ti at 56 compared with $28 \mathrm{~d}$. How do the authors explain the similar values for inter-facial strength at 28 and $56 \mathrm{~d}$ post-operative? Would they predict reduced bone/implant contact and/or reduced bone ingrowth to impact negatively on long term implant stability?

Authors: The only group with a statistically significant decrease in the amount of bone was Mac850/CoCr. There are two points to consider on this:

1) As we discussed in the manuscript, we concluded that at $28 \mathrm{~d}$ we have reached the maximum of bone growth that we could achieve. And probably this decrease in bone is due to an individual reaction. We believe that further earlier timepoints would help us to understand the dynamics better.

2) We believe, that in this specific case, this decrease may be caused by individual characteristics of one sheep that had a lower score than the other in its group. It is likely that in between sheep differences, overall biological variability and unavoidable differences in surgical precision (i.e. the quality of the press fit implantation) will affect this.

We do not believe that would predict a negative impact on long term implant stability. The reason for this belief is that we achieved good results for all the groups in the mechanical test, which is the most reliable data, when comparing porous and non-porous surfaces. Furthermore, although not statistically significant, we could observe a tendency of increase of inter-facial strength on the push out test for both TiMac structures. As we discussed, Moriyama et al. (2010) and Biemond et al. (2011a) suggest that histology assessment is not a good method for assessing the effect of bone ingrowth on mechanical strength. Correlation between bone ingrowth depth and mechanical strength of the bone-implant interface is likely to be influenced by the fact that ingrowth beyond a certain depth does not enhance the strength of the bone-implant interface, similar to that seen for the cement-bone interface (Biemond et al., 2011).

Bill Walsh: How do the authors potentially see FPS technique influencing other devices in orthopaedics, for example screws?

Authors: FPS technique was developed for ortho-devices, where multiple materials are desired at same time in the 
same component (e.g. Tibial plate $\mathrm{CoCr}$ in the sliding surface; porous $\mathrm{Ti}$ in the osseointegrative surface and eventually also with HA, ankle or other extremities components, where again the same multiple materials are desired in one component).

Bill Walsh $2^{\text {nd }}$ revision cycle: The lack of improvement with time is a bit of a concern, as the properties should improve with time. How do the authors explain this?

Authors: We believe that either integration of bone/implant has reached its maximum before the first time-point or our time-points were too close. We agree that further earlier and later time-points would help us to understand the dynamics better.

Piete Buma $1^{\text {st }}$ revision cycle: Authors state that the model is partially loaded. Can you say more about the level of loading? Is the level relevant to the first bone ingrowth process after placing a prosthesis, which is in many cased press fitted implanted? Further, to be honest, I do not believe that in this model the load is the key factor in the ingrowth of bone. It is the trauma to the bone which stimulates new bone formation from my perspective as a first reaction.

Authors: We believe that this model is partially loaded from the beginning. We cannot underestimate the muscle, ligaments, tendons and the joint movement strains over the condylar bone. Immediately after the surgery, there are already some mechanical in vivo strains from bone/ soft tissue, causing some load in the implant. This is a preliminary, partially loaded, in vivo study encouraging a fully loaded study with hip cups or tibial plateau in the future. The aim was to show the bone would grow and anchor into the implant.
As the bone is a dynamic structure, surrounded by tendons, muscles and ligaments, we believe that strains from partial deformations of bone are already acting from the beginning of implantation. And, in this case, we implanted in the femoral condyle, in the trabecular bone, close to a highly loaded joint. And the fact that the sheep were free to walk, caused load from the weight of the sheep itself. I agree, that if we had implanted in some other areas, such as done by Biemond et al. (2011), it would be a nonloaded model.

The ability of bone to grow in the surface of an implant depends on strains associate with the bone. Furthermore, for early bone ingrowth (and its acceleration), load bearing is an important factor. Maybe, this is the reason we have achieved a complete integration at 4 weeks. If there is too much or too little strain, there is no growth.

In our studies, hypotheses related to the response of tissues to materials are investigated and screened initially using a defined osseous defect in the femoral condyle. After appropriate characterisation, these would be used in functionally loaded models such as total joint replacement.

\section{Additional Reference}

Biemond JE, Eufrasio TS, Hannink G, Verdonschot N, Buma P (2011) Assessment of bone ingrowth potential of biomimetic hydroxyapatite and brushite coated porous E-beam structures. J Mater Sci Mater Med 22: 917-925.

Editor's Note: Scientific Editor in charge of the paper: Juerg Gasser. 